\title{
Measuring Risk-Adjusted Performance and Product Attractiveness of a Life Annuity Portfolio
}

\author{
Emilia Di Lorenzo $^{1 *}$, Albina Orlando ${ }^{2}$, Marilena Sibillo ${ }^{3}$ \\ ${ }^{1}$ Department of Economic and Statistical Sciences, Via Cinthia Monte S. Angelo, University of Napoli “Federico II”, Napoli, Italy \\ ${ }^{2} \mathrm{CNR}$, Istituto per le Applicazioni del Calcolo Mauro Picone, Napoli, Italy \\ ${ }^{3}$ Department of Economics and Statistics, Campus UniSa, University of Salerno, Fisciano (SA), Italy \\ Email: *diloremi@unina.it, a.orlando@iac.cnr.it, msibillo@unisa.it
}

How to cite this paper: Di Lorenzo, E., Orlando, A. and Sibillo, M. (2017) Measuring Risk-Adjusted Performance and Product Attractiveness of a Life Annuity Portfolio. Journal of Mathematical Finance, 7, 83-101.

https://doi.org/10.4236/jmf.2017.71005

Received: July 29, 2016

Accepted: January 23, 2017

Published: January 26, 2017

Copyright $\odot 2017$ by authors and Scientific Research Publishing Inc. This work is licensed under the Creative Commons Attribution International License (CC BY 4.0).

http://creativecommons.org/licenses/by/4.0/

\begin{abstract}
The paper proposes a new methodological approach for the product performance analysis into the actuarial context. Two indexes are proposed as restyled versions of the corresponding most popular ones: They have been adapted into the actuarial assessment preserving the plainness in the interpretation of the numerical results. The paper offers a practical implementation of the new approach in the case of a specific contract, containing itself innovative profiles: It concerns a life annuity in which the installments are scaled by a demographic index and contains an embedded option linked to the financial profit participating quota. It is a new life product linked at the same time to the financial and demographic volatility. The product project is studied in its profitability performance assuming stochastic hypotheses for the financial and demographic systematic risks. The indexes are implemented in a conditional quantile simulated framework and tables and graphs illustrate their trends as function of time. The results give an example of the usefulness of the proposed indexes in the phase of decisions about the product design feasibility. Moreover some suggestions concerning the consumer's perception of the contract profitability are obtained by means of a utility-equivalent fixed annuity.
\end{abstract}

\section{Keywords}

Profitability Measures, Participating Policies, Operating Income, Longevity Risk, Consumer Protection

\section{Introduction}

The new regulations currently in progress in the insurance sector make the es- 
timation procedures involving the capital amount to be allocated, according to the requirements of Solvency II, a compelling issue; a primary constraint for an insurance company is basically the entrepreneurial capability for applying the correct strategies, as regards solvency and related issues, which also accord with these guidelines. This issue is of course linked to strategic investment decisions concerning business policies, such as defining and allocating new products. The current macroeconomic environment also requires careful consideration of several variables, which impact on the ability of a company to confront adverse scenarios (see for example the stress test implemented for insurance companies in [1] and [2]). As precisely described in [3] for life annuities portfolios, a correct product management requires a fine awareness of its performance. In [4] the Authors consider a new performance evaluation model based on the market timing techniques in the case of a balanced pension plan. They point out the lack of empirical studies in these topics and highlight the relevance of this approach from several points of view, both academic and practical. Following this basic idea, in this paper we realize a risk adjusted performance measurement, developed taking into account the point of view of the insurer in the internal models realm. We perform a business project evaluation based both on the period financial result and the portfolio surplus, valued year by year. Within this context, a contractual model can be studied in the light of a performance analysis approach, which accords with the logic normally applied when valuing businesses. To this aim, we restyle two among the most popular profitability indexes in light of the actuarial assessment, which provide effective tools for the insurers' strategic information. Focusing on the life insurance sector and, in particular, life and pensions annuity products, the main issues arise from the impact of financial variables (return on investment as to premiums/contributions and reserves), as well as demographic variables. The latter are particularly valid by virtue of the improving phenomenon, which over almost two decades has been characterized by the survival trend in the industrialized countries [5]. The application of the proposed indexes has been developed in a life annuity context considering a product containing itself new contractual profiles. We get into the part of the insured during the new life product feasibility study and show the usefulness of the two new performance indicators in the decision phase. Taking into account the increasing interest of the life insurance market in longevity hedge forms, we consider a contract in which the installments of life annuities, containing an embedded option linked to the financial profit participating quota, are scaled by a demographic index as well. This is interesting since-verbatim in [6]: Demographic shifts and pressure on public insurance schemes may increase demand for life insurance as longevity has increased substantially more and faster than predicted. This new contractual scheme provides financial and demographic guarantees for the annuitants, thanks to the extension of the profit sharing system to both the risk drivers. The attractiveness of the product is considered together with a prudential capital allocation and solvency management by means of appropriate thresholds inserted in the model. The choice of this specific ex- 
ample arise from the interest of the market in variable annuities, which is going to be steady and substantial, in particular for the contractual forms with minimum guaranteed benefits [7]. Moreover, the attractiveness of the product is interesting also according to the insured's point of view. In fact planning and monitoring the safeguard of the consumer/policyholder constitute a main goal of the European Commissions aptly set up. Product distribution, information transparency and the client's degree of financial awareness ought to be suitably examined, even if this is extremely complex and requires a multi-disciplinary effort. We conclude our analysis with some suggestions aimed at measuring the perception of contract profitability within the expected utility approach, so obtaining a wider perspective of the overall dynamics of the contract, which takes into account both the insurer's profitability, as well as the market attractiveness.

The paper is organized as follows: in Section 2 the profit and risk parameters are presented and discussed; in Section 3, aiming at an applicative procedure of the scheme proposed in the previous section, the new contract architecture is defined and the two indexes are specified in their expression in the considered contractual case; in Section 4 the model is implemented in a stochastic context for both the financial and demographic risk drivers. The performance analysis is developed by means of simulating techniques within a conditional quantile framework and numerical evidences are collected in tables, illustrating the profitability index behavior as a function of the contract duration. In Section 5 an analysis of the insured's point of view is considered. In Section 6 some final conclusions are given.

\section{Profitability Indexes for Life Annuity Business}

The company's performance and its overall efficiency are well described by the profitability ratios in [3], framed within a life annuity portfolio. In order to get a meaningful and effective description of the financial situation of this specific business-line, it is necessary to take into account its nature, in an actuarially authenticated way. This means we will consider the risk sources typical of that kind of business and the dynamic framework in which the financial and demographic relationships evolve, paying particular attention to the impact on the obligation flows between insured and insurer. The financial quantity around which we choose to define the analysis is the surplus as in [8] [9] [10] studied as a function of time, in both its structural components of retrospective gain and prospective loss. The profitability measures we are going to propose in what follows, are the actuarial expressions of classical financial profitability indexes, commonly used in approaches which value businesses. This approach will allow us to achieve numbers characterized by very interesting and easily communicable meanings, without altering the peculiar nature of the contract. For these reasons, our indexes will be always identified by the adjective actuarial, to evidence that the calculation structures have been built upon the principles of actuarial appraisal.

In light of these considerations we propose a new version of two traditional and popular profitability indexes [8], i.e. Return on Equity (ROE) and Return on 
Asset (ROA), restyling them as Actuarial Return on Equity (AROE) and the Actuarial Return on Gain (ARG), both in their stochastic formulation. Some considerations about these ratios are here briefly stated.

As with the ROE index, the AROE, referring to one balance sheet year, is given by the ratio of profit to equity. When AROE is employed and its results are studied as performance measures, essential to the aim of an efficient financial interpretation is how the profit and the equity are valued. We will construct the ratio setting as numerator the profit the company achieves through its business and as denominator the surplus the business provides, in the context referred to above (the difference between prospective loss and retrospective gain). The valuations at time $t$ are relative to the beginning of the $t$-th year in a forward perspective, in the sense that the information flow the insurer is given is at hand at time 0. The numerical results for AROE express how much the total amount collected by the insurer to manage the product yields in a certain time interval. This is a very common profitability measure, quick to communicate and easily interpreted, for which good performances will be represented by high percentages.

The second index we will deal with is based on the Return on Asset concept. This ratio seems to be very informative in the case of annuities as they are contracts producing large assets, especially if compared with other kinds of life insurance contracts. As suggested in [11], in these cases a good profit measure is the Return on Asset, that is the ratio between net income and total asset, valued, as for the ROE, within one balance sheet year. In this approach, the index we will construct identifies the amount of profit made per unit of retrospective gain the business produces, having considered the stochastic asset valuation in the form of net retrospective gains arising from the contract. Consequently, the index can be expressed as the Actuarial Return on Gain (ARG).

The results derived for this index quantify the efficiency the company achieves in using the assets arising from the product under consideration. The ARG index measures the efficiency the company shows in managing its investment in assets for generating profit and of course in this case too, the higher the percentage, the better. The actuarial calculations will be performed in a forward perspective. In this case, as with the AROE, useful indications can be deduced from the description of the evolution over time of the stochastic process ARG. These include the measure of how profit is yielded from the financial resources invested in the product itself.

\section{The Performance Analysis in the Case of a Novel Participating Life Annuity Contract}

We develop the application of the proposed performance analysis to a specific contract, falling under the category of the participating policies. The contract contains innovative characteristics, interesting within the financial and demographic scenarios in which the insurance activity is performed.

When a country's financial systems provide strong social security, the demand 
for voluntary life annuity is rather soft as a consequence. On the contrary, because of the contemporary financial crisis affecting the majority of Western economies, the present scenario is characterized by a weak social security system. In such situations, an increasing demand for voluntary life annuity as supplementary pension or pension fund arises [12]. This growing trend is also due to a deeper perception of longevity improvement, inducing more persons to a prudential management of their financial status at older ages. If these insurance contracts, in contrast to the classic rigid ones, present also elements of flexibility, responding to the current dynamics and volatile financial environment, they can potentially become interesting and desirable tools.

From the actuarial evaluation viewpoint, the participating business, when connected to a pension annuity policy, triggers a complex contractual structure. Correct contract management requires a fine awareness, applied at the time of issue, of the evolution in time of both the insurer's obligations and the income capabilities or, more synthetically, a competent awareness of the design of the payment phase, as is pointed out in [13]. The analysis turns on the actuarial control of the periodic financial margins arising from the management of the policy [14]. This notion adds up to the main issues in participating life contracts, characterized by long-term liabilities valued on the basis of assumptions about the future. The margins and their distribution have to be forecast in a plan extending over a wide time interval: this brings about the central role of margin calculation in product design. The general formula, explaining the margin value at time $t$ and all the risk sources influencing it, can be formulated in the following general expression, well known in Actuarial Theory:

$$
\begin{aligned}
\operatorname{margin}(t+1)= & {[\operatorname{Premium}(t)+V(t)](1+i)-p[\operatorname{Benefit}(t+1)+V(t+1)] } \\
& - \text { Expenses and Taxes }(t+1)
\end{aligned}
$$

where $p$ is the probability that the annuitant is living at time $t+1$ and $i$ is a suitable interest rate. The formula clearly shows that the margin in $t+1$ comes from the insurer's obligations-in case of life-to pay the Benefit and constitute the reserve $V(t+1)$ at time $t+1$, constituted by the Premium eventually collected together with the reserve at time $t$, both capitaoized. Expenses and taxes have to be subtracted.

In the paper we will assume that the annuitants participate in the investment profit and in the mortality experience, thus transferring both the financial and the demographic volatility to capital markets, in a profit sharing mechanism. The benefit amount, although influenced by the volatility in financial and demographic scenarios, will be constrained within appropriate limits, as guarantees for both insured and insurer.

As long ago as 2007, [3] precisely describe, in the case of life annuity portfolios too, that a correct product management begins with the identification of its sources, clearly pointed out in formula (1). Firstly, we can observe that premiums required in case of non-participating policies will be lower than those in case of participating contracts. This means that, ceteris paribus, premium rates 
themselves are margin makers. To this, other margin sources have to be added: investment and capital gains, higher mortality than expected (very incisive in long term contracts with payments to survivals), and finally lower expenses than estimated. In particular, considering, as suggested in [11], that the insurer presumably invests in equities, the question of the margin distribution dynamics among the insureds is elaborate and workable in several ways.

From the perspective of prudential fund management, within the context of fair safeguarding of the insureds' rights, the kind of margin the insureds participate in is specified for each life annuity participating product. From these general observations, participating life annuity structures are different from country to country and they can even differ among insurance companies of the same country. Recently [15] analyzes German participating life annuities (PLA) with guaranteed minimum benefits and participation in insurers surpluses; in particular in the paper the Authors investigate the lifetime utility of annuitants buying PLAs, taking into account insolvency risk related to such contracts.

The contract we are going to propose is a life annuity characterized by installments contextually containing an imbedded option linked to the financial margin participating quota and an indexation by a demographic ratio. The monetary amount we call margin has to be accurately handled. Insurers are institutionally required to maintain minimum solvency margins for facing future risk, thus guaranteeing their solvency. Therefore, the margin has to be considered not only as an amount to distribute but, first of all, as the amount to reserve and to accrue for adverse evolution of the business due to its randomness. From these considerations, a very careful quantification of the margin participating quota has to be realized. The participating quota has a very meaningful strategic role: the insurer has to attribute to it the right value, realizing a form of equilibrium between, on one hand, its solvency obligations and the advantages of keeping more money free to invest in several industrial activities (new product perspectives, new strategic possibilities) and, on the other hand, the advantages of distributing more money to the insureds (serving the aims of competitiveness and product attractiveness).

The careful choice of the participating quota impacts on the premium calculation and on the profitability results. This choice can be performed by means of scenario analysis based on variable values of the participating quota, as shown in the numerical example in Section 4. Moreover, from the insureds point of view, the attractiveness of the product is based on the clear knowledge of the minim value of the installments guaranteed by the threshold inserted in the contract. There is little doubt that the non-systematic demographic risk component, also called micro-longevity risk [16] [17] can easily be managed by means of pooling techniques, in contrast with the systematic demographic component (macro-longevity risk). This latter, arising as it does from a general improvement in the trend of mortality, impacts on all policies in the portfolio, in the same direction [12]. Managing this risk component is a crucial challenge for insurers and the choice of an appropriate technique is not easy. Apart from balancing hedg- 
ing techniques (consisting of a sort of compensating effect between opposite demographic risks within a portfolio) and reinsurance (where the correlation between relative cost and risk interest emerges), a valuable tool is to transfer the demographic risk to the capital markets, considering survival as an asset. As the literature widely confirms, it must be pointed out that this derivative market continues not to be completely developed and cannot yet provide an appropriate response to the needs of insurance coverage. In recent actuarial literature, alternatives to securitization have often been put forward, in the context of certain types of contracts already in force within health insurance plans [18]: such alternatives consist of the construction of suitable survival-indexed annuities. In particular, [18] describes annuities indexed to mortality in which the transfer of the insured risk is largely mitigated by the presence of a terminal bonus. [19], on the basis of insurance contracts issued in the United States by the Teachers Insurance and Annuity Association (TIAA), propose a kind of group self-annuitization, where the group of annuitants creates a fund for the guarantee of longevity. In particular, in [20] the Authors aim at matching the definition of installments with survival behavior trends. At the same time the annuitants are protected from the excessive impact of the systematic risk, which they share with the insurer by means of appropriate variation of parameter thresholds associated to survival dynamics.

According with the aforementioned overview, we now consider a contractual scheme in which the installments contain the embedded option linked to the financial margin participating quota and are scaled by a demographic index based on the ratio between the forecast projected survival trend and the observed one.

\subsection{The Contractual Architecture}

Following the basic line in [20], we assume that the benefits due throughout the contract to each annuitant aged $x$ at issue, if alive at the payment time $t$, are adjusted by the scale factor:

$$
S I_{x, t}=\frac{{ }_{t} p_{x}^{\text {proj }}}{{ }_{t} p_{x}^{\text {obs }}}
$$

where ${ }_{t} p_{x}^{\text {proj }}$ is the survival probability for an annuitant aged $x$ being alive at age $x+t$, inferable from a proper projected demographic model, and ${ }_{t}{ }_{x}^{\text {obs }}$ is the analogous survival probability deduced from the observed data. In particular the insurer, referring to the cohort of annuitants aged $x$ at contract inception, at each payment time $t$, compares the probability ${ }_{t} p_{x}^{\text {proj }}$ (previously estimated by means of a projected model) to ${ }_{t}{ }_{x}^{\text {obs }}$, being referred to the fraction of the population which is still living at time $t$. Moreover we assume:

$$
S_{t}=\max \left\{\min \left\{S I_{x, t}, S I_{\max }\right\}, 1\right\}
$$

where $S I_{\max }$ represents the maximum level obtained by an appropriate contractual equilibrium between marketing appeal and capability to meet the demographic risk.

Then, within the context of a market, where insurance policies with profit 
currently represent an interesting potential in the insurance sector, we add in the contract the participation of the insured to the financial profits eventually arising from the investments. In this framework, we assume that the profit sharing is based on the differences among income, capital gains and losses [5].

On the basis of the aforementioned considerations, we propose a new model, where, together with the longevity risk sharing structure, we introduce a participation rate applied to financial result for the period, following the lines in [8]. In particular we consider an embedded option: if the period financial result $R_{t+1}$ of the interval $[t, t+1]$, net of the annual quota of the administrative expenses (say $\gamma$ ), is positive, then a bonus is added to the provision allocated in $t+1$. The bonus is equal to a percentage $\alpha$ of $\left(R_{t+1}-\gamma\right)$ and increases the future benefits for the policyholders, paid immediately or added to future installments.

So, the benefit flow $\tilde{b}_{t}$ payable to the insureds can be represented as follows:

$$
\tilde{b}_{t}= \begin{cases}b_{t} S_{t}+\alpha\left(R_{t}-\gamma\right) & \text { if }\left(R_{t}-\gamma\right)>0 \\ b_{t} S_{t} & \text { if }\left(R_{t}-\gamma\right) \leq 0\end{cases}
$$

where $b_{t}$ is the basic installment. Equation (4) guarantees at least the basic installment to the annuitant. The architecture of the annuity described above achieves a balance market appeal on the part of annuitants, who focus on the financial competitiveness of their investments, and the point of view of the insurers, who pay attention to profitability combined with decreasing levels of risks.

According to the scheme described and recalling [8], at the issue time $t=0$, let the insurer be provided with forward information regarding interest rates, as well as on the number of survivors at each time $t$. Let us indicate with $\{v(t, s)\}$ the stochastic process describing the value at time $t$ of one monetary unit at time $s$. We consider the case of a life annuity with deferment period $T$, premium payment at the beginning of each year until the time $\tau(\tau<T)$ and annual installments $\tilde{b}_{s}$ given by (4) due at the beginning of year $s(s \geq T)$. The stochastic provision at time $t$ is:

$$
V_{t}=\sum_{i=t}^{\infty}\left(\tilde{b}_{i} 1_{(T \leq i \leq K(x))}-P_{i} 1_{(i<\tau / K(x)>i)}\right) v(t, i)
$$

The indicator function $1_{(T \leq i \leq K(x))}$ takes the value 1 if $T \leq i \leq K(x) \quad(K(x)$ being the random curtate lifetime of an annuitant aged $x$ at the issue time of the contract), 0 otherwise, whilst the indicator function $1_{(i<\tau / K(x)>i)}$ takes the value 1 if $i<\tau$ if the insured is alive, 0 otherwise.

We pose the financial result $R_{t+1}$ of the $(t+1)$-th accounting period as follows:

$$
R_{t+1}=\left(V_{t}+P_{t} 1_{(i<\tau / K(x)>i)}\right) v(t+1, t)-\left(\tilde{b}_{t+1}+V_{t+1}\right) 1_{(T \leq t+1 \leq K(x))} .
$$

If $R_{t+1}$ is greater than $\gamma$, the insurer pays the additional bonus $\alpha\left(R_{t+1}-\gamma\right)$ to the insured $(0<\alpha<1)$.

Hence we can write the total $(t+1)$-th financial result $T R_{t+1}$ as:

$$
T R_{t+1}=R_{t+1}-\alpha\left(R_{t+1}-\gamma\right)^{+}=\min \left(R_{t+1},(1-\alpha) R_{t+1}+\alpha \gamma\right)
$$

and the surplus at time $t+1$ is: 


$$
S_{t+1}=\sum_{j=0}^{\infty} X_{j} v(t+1, j)
$$

where

$$
X_{j}=\left(P_{j} 1_{(j<\tau / K(x)>J)}-\tilde{b}_{j} 1_{T \leq j \leq K(x)}\right) \operatorname{sign}(t-j)
$$

\subsection{The New Indexes in the Contractual Case}

The two indexes presented in Section 2 are specified in the contractual case described in Section 3.1. We can express the $A R O E$ index as the ratio between profit to surplus:

$$
\operatorname{AROE}(t+1)=\frac{R_{t+1}-\alpha\left(R_{t+1}-\gamma\right)^{+}}{\sum_{j=0}^{\infty} X_{j} v(t+1, j)}
$$

with $R_{t+1}$ the financial result of the $(t+1)$-th accounting period.

Within a managerial context, information about the trend of the stochastic process $A R O E$ can be particularly useful if applied to asset management policy, for example in choosing the profit-participation level or setting the cap and floor boundaries.

The $A R G$ index is

$$
\operatorname{ARG}(t+1)=\frac{S_{t+1}}{R G_{t+1}}
$$

with $S_{t+1}$ given by formula (7) and $R G_{t+1}$ the retrospective gain produced by the life annuity contract at time $t+1$, that is:

$$
R G_{t+1}=\sum_{s=0}^{K(x) \wedge t} X_{s} v^{-1}(s, t+1)
$$

where $x \wedge y=\min (x, y)$ and $K(x)$ the random life-time of an individual aged $x$.

\section{The Performance Analysis}

\subsection{Basic Assumptions}

In this section we want to show how the profitability indexes presented in Section 2 can describe the performance of a homogeneous portfolio of policies structured as proposed in Section 3. We refer to a portfolio of 1000 immediate annuities, with deferred installments, issued to lives aged 65. In this application each insured pays a single premium at the issue time (the example can be easily extended to the case of a deferred life annuity with periodic premiums). The pure premium paid by each insured will be calculated at a fixed technical rate and according to a suitable projected probability law, taking into account the variable installments of the described contractual architecture, the assumption is that the benefits due to each annuitant, if alive at the payment time, are adjusted by the scale factor defined in (2) and increased by $\alpha\left(R_{t+1}-\gamma\right)$, if positive. In order to investigate the values of the survival ratio in formula (2), based on the comparison between the observed survival probabilities and the forecast ones, we consider the period from 1970 to 2009 in our assumptions. We use Italian 
male survival annual rates: the observed probabilities at the denominator are drawn by the Human Mortality Database website and we choose to describe the probabilities at the numerator by the Lee Carter model $^{1}$ with parameters estimated as in 1970, on the basis of the dataset available at that date.

Figure 1 shows the trends of the Lee Carter parameters estimated on the dataset ranging from 1872 to 1969 . In particular, and clockwise, the first and the second graphdisplay typical patterns of $\alpha_{x}$ and $\beta_{x}$ estimated by implementing SVD (singular value decomposition) where the $\beta_{x}$ 's are scaled so that they sum to unity. The third graph has been obtained by a random walk with drift for forecasting the time-varying parameter $k_{t}$. The Lee-Carter forecast is referred to the period 1970-2009. In Figure 2 we report the log death rates obtained by the Lee Carter projection, as above described, when age varies. The lowest curve describes the log death rates trend in 1970 while the highest one describes the same trend in 2009. In Figure 3 we show the comparison between the annual survival rates for a man aged 65 in 1970 extended from age 65 to age 104. As evident in Figure 3, the Lee Carter probabilities match well the observed data till the age 80 , when the estimated values become notably higher than the observed ones.

In Figure 4 the trend of the longevity index for a man aged 65 in 1970 is shown.

In order to limit the impact of this index on the annuity payments, we assume $S I_{\max }=1.2$, then the benefit at time $t$ is:

${ }^{1}$ The Lee-Carter (LC) model [21] involves the logarithm of the mortality rate at a given age $x$ in a given year $t$, as follows:

$$
\ln m_{x, t}=\alpha_{x}+\beta_{x} k_{t}+\varepsilon_{x, t}
$$

with

$-m_{x, t}=$ death rate at the agex in the year $t$

$-\alpha_{x}=$ age-specific component (not dependent on time) at age $x$

$-\beta_{x}=$ age-specific component (not dependent on time), which incorporates mortality variations linked with variations of the general mortality level (sensitivity parameter)

$-k_{t}=$ time component which expresses the general mortality level in year $t$

$-\varepsilon_{x, t}=$ error term with zero mean and finite variance.

In particular, $\alpha_{x}$ is the mean of $\ln m_{x, t}$ throughout the observation period. In order to estimate the parameters, Lee and Carter used the following normalizing positions: $\sum_{t} k_{t}=0$

so:

$$
\bar{\alpha}_{x}=\frac{\sum_{t} \ln m_{x, t}}{n}=\ln \left(\prod_{t} m_{x, t}\right)^{\frac{1}{n}}
$$

and

$$
\sum_{x} \beta_{x}=1
$$

hence

$$
\bar{k}_{t}=\sum_{t} \ln m_{x, t}-\sum_{x} \alpha_{x}
$$

$\bar{\beta}_{x}$ can be obtained by a linear regression and:

$$
\ln \bar{m}_{x, t}=\bar{\alpha}_{x}+\bar{\beta}_{x}
$$

Lee and Carter modeled $k_{t}$ by means of an $\operatorname{ARIMA}(0,1,0)$ process. 
$\tilde{b}_{t}=b_{t} \max \left\{\min \left\{S I_{x, t}, 1.2\right\}, 1\right\}$ and for simplicity purposes we set $b_{t}=1$. The AROE and ARG functions are based on investment and discounting operations. Within the performance analysis from the insurer's point of view, for describing both the evolution in time of the rate of return on investment of collected premiums and the dynamics of the discounting rate required for valuing the reserves, we choose the Vasicek mean reversion model [22]:

$$
\mathrm{d} r_{t}=\beta\left(\mu-r_{t}\right) \mathrm{d} t+\sigma \mathrm{d} W t
$$
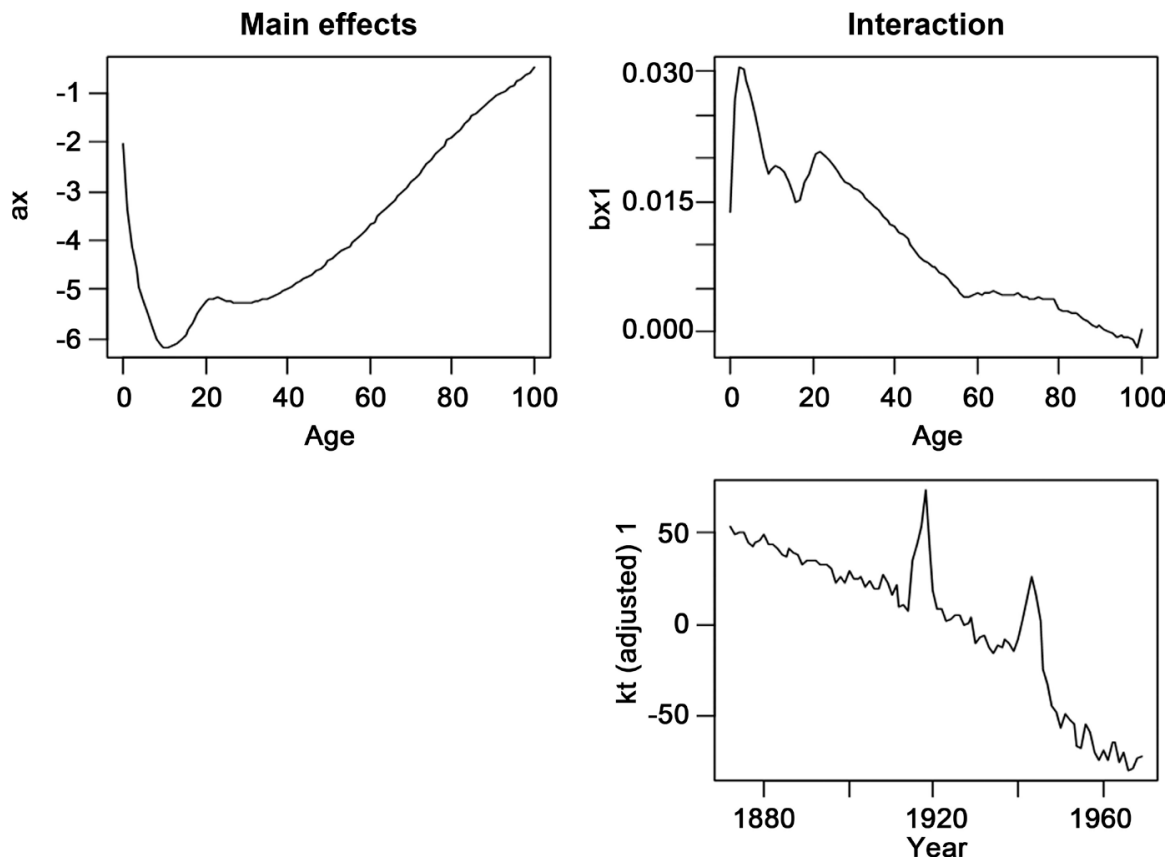

Figure 1. Lee carter perameters.

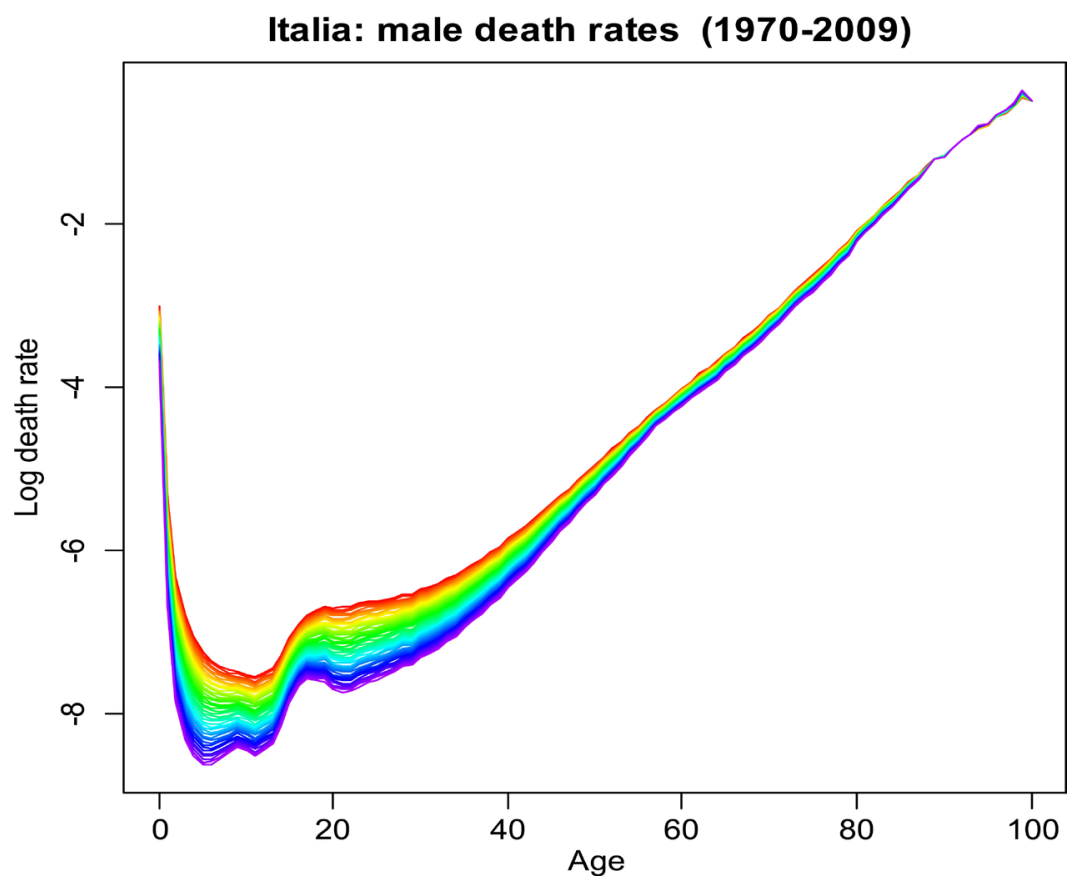

Figure 2. Log death rates curves for different reference years. 


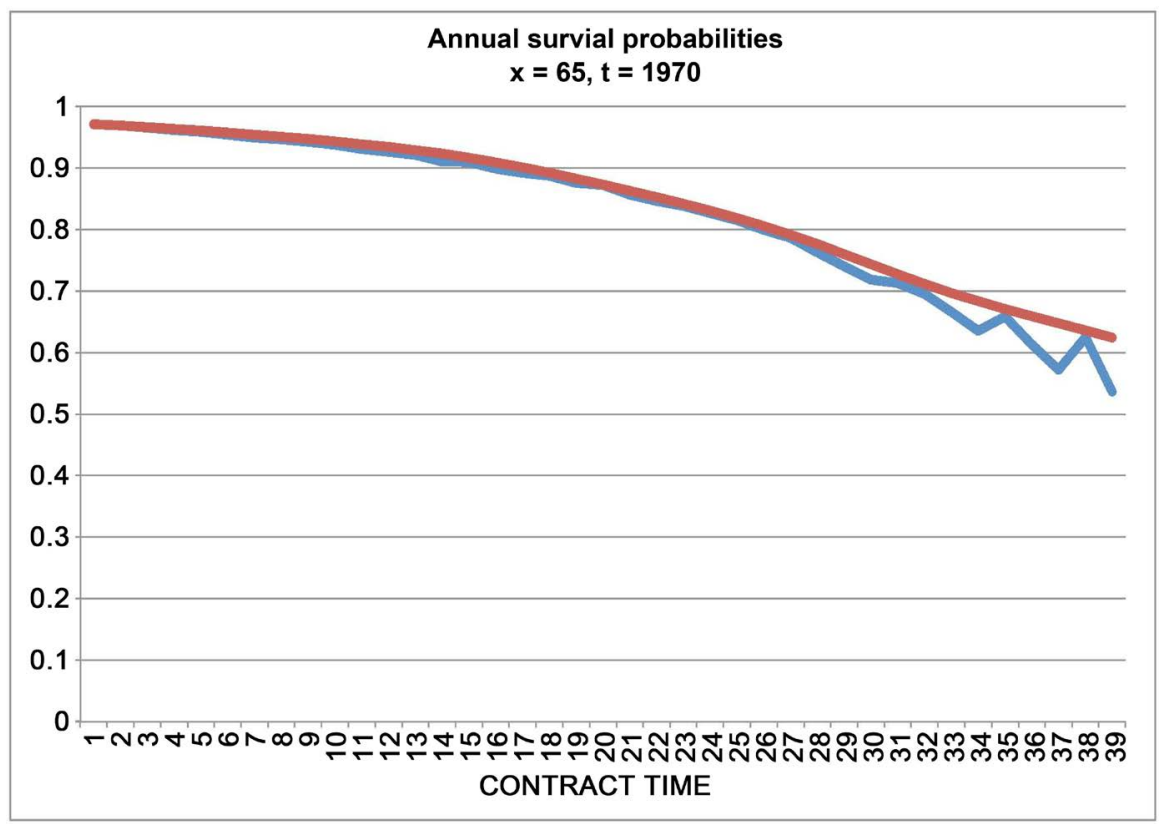

Figure 3. $t p_{x}^{o b s}, L C_{t} p_{x}(x=65)$.

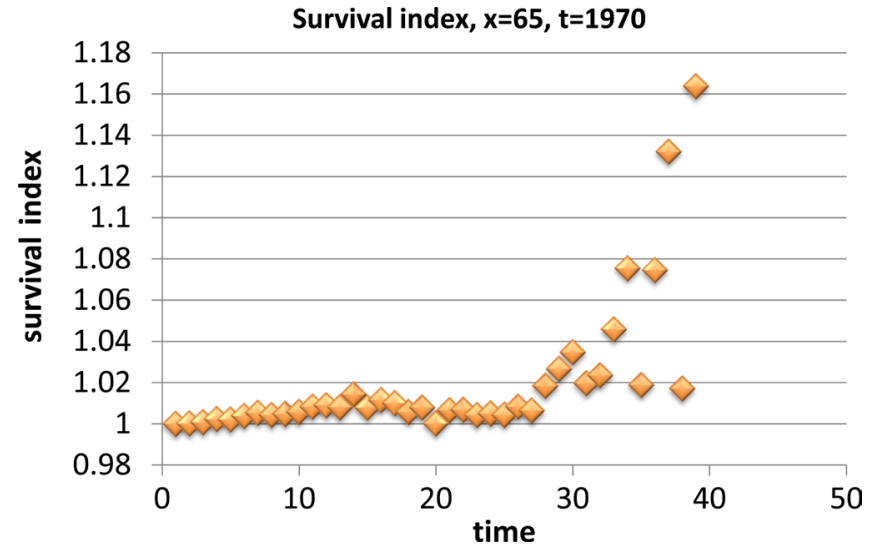

Figure 4. Index behaviour.

with $\beta, \mu$ and $\sigma$ positive constants and $W_{t}$ a standard Wiener process. Of course we calibrated the model coherently with the demographic hypotheses and we refer to the monthly yield over the period January 1960-January 1970, on a basket of Treasury Italian bonds. Such parameters are reflecting the results of the insurer's actual investment strategy. So we obtained $\mu=0.0389, \beta=0.3263$, $\sigma=0.054$. We pose the annual expenses of the portfolio equal to 60 . The single premium is calculated at the technical rate of $2 \%$ and on the basis of the aforementioned Lee-Carter model, considering two specific values for $\alpha$, i.e. $\alpha=20 \%$ and $\alpha=80 \%$.

\subsection{Numerical Evidence: AROE and ARG Stochastic Assessment in a Conditional Quantile Simulation Framework}

The numerical analysis was performed using the conditional quantile technique carried out by a simulation procedure applied to the empirical distributions of 
the stochastic variables AROE and ARG as described in section 3.2 and studied in function of the time. Fixing a threshold value depending on the confidence interval, the results were interpreted as the worst cases scenarios with an occurrence probability lower than the threshold and their average can be regarded as the expected worst occurrence corresponding to that level of confidence. Moreover the values for expected ARG and AROE was interpreted as measures of mean profitability per policy.

Beginning with the AROE index, the simulation procedure was implemented with 10,000 AROE values for each $t$ and the expected values and the C-quantiles with confidence level 0.95 and 0.99 were obtained. The results, calculated in $t=0,5,10,15,20,25,30,35,40$ are shown in Table 1 , where we considered an annuitant aged 65 and a participating quota equal to $20 \%$. In particular we report the behavior of the maximum and minimum AROE values obtained for each $t$ by the simulation procedure and the expected values calculated as the mean of the 10,000 simulated values. In the same table we report the C-quantile values choosing the confidence intervals of $95 \%$ and $99 \%$. The decreasing behavior of the expected AROE and its $\mathrm{C}$-quantiles still show a decreasing inclination tending to stabilize for high values of $\mathrm{t}$. Table 1 outlines the expected AROE stationary around $1.4 \%$ while for the C-quantiles at $95 \%$ and $99 \%$ respectively at $1.38 \%$ and $1.36 \%$. Table 2 shows the numerical results in the case of a participating quota equals to $80 \%$. A marked reduction of all the values is evident: as an example, the stationary value for the $\mathrm{C}$-quantiles goes down to $0.3 \%$.

Likewise for the AROE, the ARG analysis was performed by a simulation procedure for getting the empirical distribution of ARG values for each $t$, implemented on 10,000 ARG outputs for each value of $t$. Again in the case of an annuitant aged 65 and the participating quota of $20 \%$, Table 3 shows the values calculated in $t=0,5,10,15,20,25,30,35,40$. We report the expected ARG values with the related minimum and maximum and the C-quantiles at $95 \%$ and $99 \%$. The trend is definitely increasing, in this case too with a decreasingly weak inclination towards a stable value for high durations. In particular in Table 3 the stable value is around $1.5 \%$ for the expected ARG and about $1.35 \%$ for the Table 1. Expected AROE and conditional quantiles, $\alpha=0.2$.

\begin{tabular}{cccccc}
\hline$t$ & $E[$ AROE $] \%$ & Minimum & Maximum & $c q(0.95)$ & $c q(0.99)$ \\
\hline 0 & 2.34542 & 1.87298 & 3.34245 & 2.19645 & 2.00290 \\
5 & 2.00863 & 1.57663 & 3.51297 & 1.95231 & 1.93460 \\
10 & 1.64217 & 1.36129 & 2.57190 & 1.62701 & 1.60120 \\
15 & 1.58753 & 1.24358 & 2.15253 & 1.57734 & 1.52347 \\
20 & 1.50907 & 1.24286 & 2.04465 & 1.48923 & 1.45209 \\
25 & 1.45953 & 1.22108 & 1.86286 & 1.44100 & 1.42147 \\
30 & 1.43741 & 1.21368 & 1.82375 & 1.42253 & 1.40054 \\
35 & 1.41934 & 1.20237 & 1.79042 & 1.40866 & 1.38234 \\
40 & 1.39442 & 1.20857 & 1.78789 & 1.38342 & 1.36479 \\
\hline
\end{tabular}


Table 2. Expected AROE and conditional quantiles, $\alpha=0.8$.

\begin{tabular}{cccccc}
\hline$t$ & $E[$ AROE] $\%$ & Minimum & Maximum & $c q(0.95)$ & $c q(0.99)$ \\
\hline 0 & 0.67479 & 0.34287 & 1.68634 & 0.66452 & 0.65280 \\
5 & 0.53243 & 0.25872 & 1.55239 & 0.51239 & 0.50342 \\
10 & 0.47354 & 0.20432 & 1.49752 & 0.46231 & 0.45265 \\
15 & 0.42496 & 0.15321 & 1.45321 & 0.40856 & 0.39312 \\
20 & 0.37553 & 0.12865 & 1.40729 & 0.34569 & 0.33264 \\
25 & 0.36333 & 0.11867 & 1.39634 & 0.35001 & 0.33142 \\
30 & 0.35233 & 0.11745 & 1.38634 & 0.31987 & 0.30963 \\
35 & 0.35005 & 0.10998 & 1.37523 & 0.31867 & 0.30856 \\
40 & 0.34758 & 0.09723 & 1.37231 & 0.30645 & 0.30021 \\
\hline
\end{tabular}

Table 3. Expected ARG and conditional quantiles, $\alpha=0.2$.

\begin{tabular}{cccccc}
\hline$t$ & $E[\mathrm{ARG}] \%$ & Minimum & Maximum & $c q(0.95)$ & $c q(0.99)$ \\
\hline 0 & 0.89367 & 0.87739 & 0.91924 & 0.89418 & 0.87922 \\
5 & 0.97520 & 0.96826 & 1.00013 & 0.96401 & 0.96031 \\
10 & 1.15109 & 1.15108 & 1.19647 & 1.02297 & 0.98735 \\
15 & 1.27279 & 1.19356 & 1.39885 & 1.20453 & 1.19428 \\
20 & 1.36341 & 1.24928 & 1.57392 & 1.28398 & 1.25465 \\
25 & 1.42728 & 1.28308 & 1.74562 & 1.32298 & 1.29120 \\
30 & 1.48836 & 1.29481 & 1.81914 & 1.34175 & 1.32631 \\
35 & 1.50740 & 1.31042 & 1.87954 & 1.36789 & 1.32962 \\
40 & 1.52289 & 1.31896 & 1.90108 & 1.37072 & 1.34907 \\
\hline
\end{tabular}

Table 4. Expected ARG and conditional quantiles, $\alpha=0.8$.

\begin{tabular}{rccccc}
\hline$t$ & $E[\mathrm{ARG}] \%$ & Minimum & Maximum & $c q(0.95)$ & $c q(0.99)$ \\
\hline 0 & 0.25386 & 0.24317 & 0.27967 & 0.24985 & 0.243775 \\
5 & 0.28530 & 0.26984 & 0.29764 & 0.27452 & 0.26987 \\
10 & 0.31086 & 0.27862 & 0.33275 & 0.30845 & 0.28653 \\
15 & 0.33818 & 0.27923 & 0.40243 & 0.32579 & 0.31289 \\
20 & 0.40325 & 0.29456 & 0.44276 & 0.33478 & 0.32674 \\
25 & 0.45926 & 0.31645 & 0.63407 & 0.34679 & 0.33376 \\
30 & 0.51820 & 0.32032 & 0.71324 & 0.36417 & 0.35786 \\
35 & 0.52083 & 0.33631 & 0.76497 & 0.38785 & 0.36897 \\
40 & 0.52331 & 0.33953 & 0.77428 & 0.39002 & 0.37634 \\
\hline
\end{tabular}

C-quantiles. Table 4 reports the values when the participating quota is $80 \%$. In this case the stationary value reduces to about $25 \%$ similarly to the AROE case.

\section{Some Considerations about the Insureds' Point of View}

In this section we provide some brief guidelines about the consumer's point of 
view.

Consumer protection is one of the main concerns within the current activities of the Committee on Consumer Protection and Financial Innovation (CCPFI) of the European Insurance and Occupational Pension Authority (see for instance [23] and [24].

This problem invests into areas concerning vigilance over products and governance systems. The current financial literature is paying increasing attention to the varied world of decision making under uncertainty from the insured's perspective. The many aspects of the question are treated by means of different approaches, which range from the expected utility theory to methodologies of behavioral finance as in [25].

[15] proposes an utility approach, by means of a Constant Relative Risk Aversion (CRRA) function, in order to value the insured's profitability in the case of a specific contract, that is a German participating life annuities (PLA) with guaranteed minimum benefits and participation in insurer's surpluses. Now, just following this approach, we provide some suggestions concerning the contract proposed in Section 3. As in [15], we consider a CRRA utility function applied to a life annuity with benefit flow defined by (4) and duration of 10 years, issued to an insured aged 65 . The utility expected by the benefit stream is given in [26].

$$
U=E\left[\sum_{i=1}^{\omega-x-1} \phi_{i}^{i} p_{x} \frac{\tilde{b}_{i}}{1-\gamma}\right]
$$

with $\gamma$ the relative risk aversion, $\phi$ the discount factor arising from the insureds subjective preferences. With reference to the numerical example presented in the previous section, we consider three different risk aversion levels, which represent, respectively, low, medium and high risk aversion $(\gamma=2,5,10$, respectively) as in [15], together with three values of $\phi, 0.98,0.96,0.94$, referred to patient/normal/impatient individuals, respectively.

Table 5 provides the utility equivalent annuities (UEAs) calculated in the case of a fixed interest rate 0.02 ; Table 6 provides the UEAs in the case of stochastic interest rates described by the Vasicek process introduced in section 4.1.

In both the two tables it is evident that the installments of all the UEAs decrease with an increasing risk aversion, whilst they increase with a decreasing patience level. The constant installments obtained for the UEAs are greater than 1 , as a consequence of the peculiarities of the equivalent insurance contract.

For every fixed impatience level, when the risk aversion increases, the constant installments of the UEAs decrease; this is congruent with a high risk aversion, which implies low installments, while avoiding randomness.

For every fixed aversion level, on the contrary, lower impatience is satisfied by lower installments.

All the values in Table 6 are higher than the analogous in Table 5.

The overall trend of the expected utility is shown in Figure 5, where the Expected Life-Time Utility is designed for the three different values of $\gamma$ and for $\phi$ varying; we observe higher values corresponding to high degree of impatience, apart from the risk aversion. In the figure, the impact of the different le- 
vels of risk aversion consists in increasing values the Expected Life Time Utility for fixed values of $\phi$ when $\gamma$ decreases.

It is also evident that the expected utility strictly decreases when the subjective discount factor increases.

A further discerning aspect could depend on the premium amount in the cases of utility-equivalent certain annuities, consistently with their risk aversion and impatience profile. In Table 7 we report the single premiums in four meaningful

Table 5. UEAs, $i=2 \%$.

\begin{tabular}{cccc}
\hline $\begin{array}{c}\text { Subjective } \\
\text { discount factor }\end{array}$ & Low risk adverse & Medium risk adverse & High risk adverse \\
& $\gamma=2$ & $\gamma=5$ & $\gamma=10$ \\
\hline$\phi=0.98-$ patient & 1.214637 & 1.188294 & 1.140241 \\
$\phi=0.96-$ normal & 1.236498 & 1.192035 & 1.167642 \\
$\phi=0.94-$ impatient & 1.253928 & 1.203672 & 1.173338 \\
\hline
\end{tabular}

Table 6. UEAs, Vasicek process.

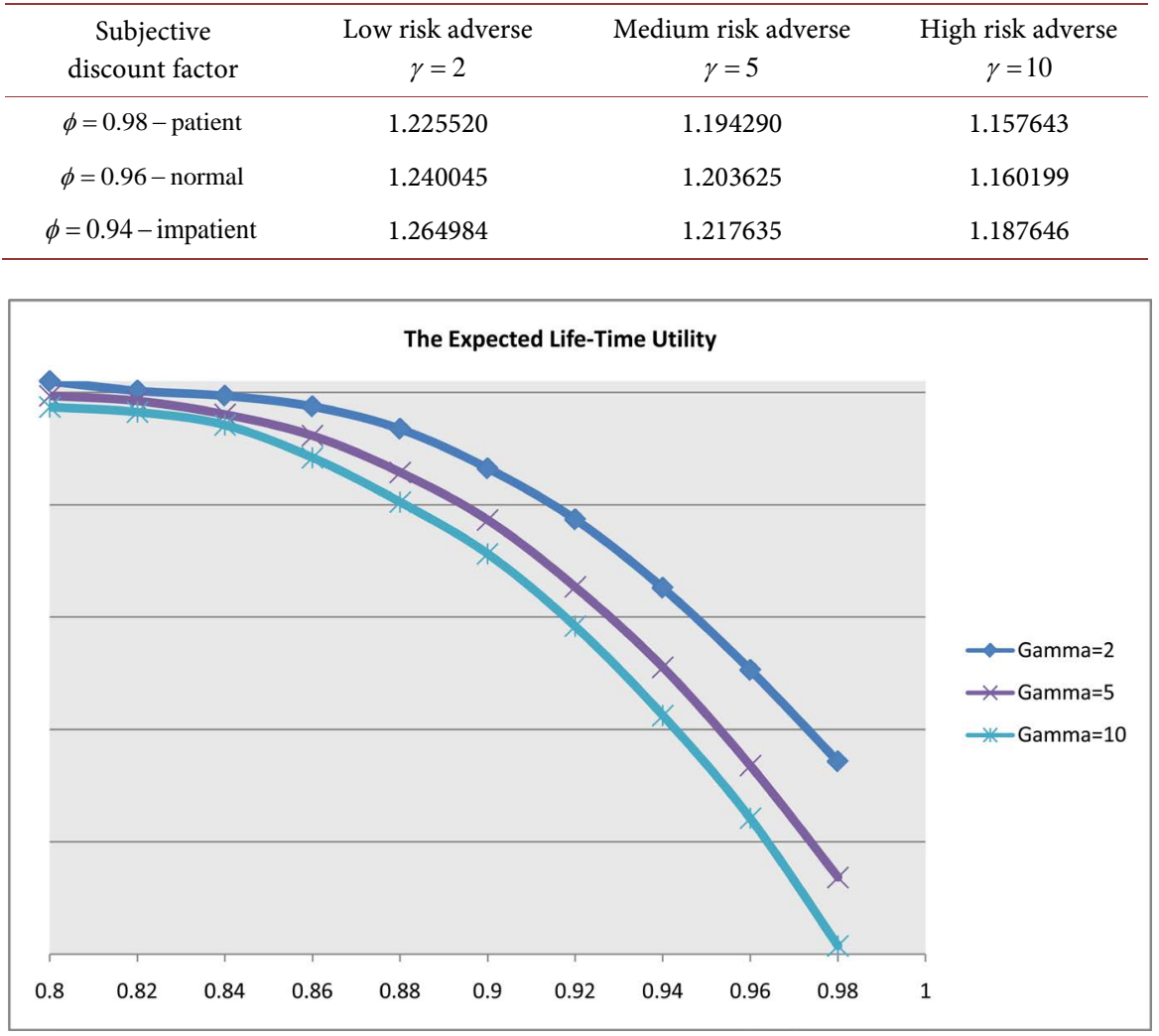

Figure 5. The expected lifetime utility, $\varphi$ varying from 0.8 to 0.99 .

Table 7. Premium amounts.

\begin{tabular}{cc}
\hline Annuity & Premium \\
\hline Participating life annuity - Financial and demographic indexing & 8.214 \\
Participating life annuity - Financial indexing & 8.055 \\
Constant life annuity & 7.985 \\
Utility-equivalent annuity - normal individuals with medium risk aversion & 9.582 \\
\hline
\end{tabular}


cases as follows:

1) the ten-years annuity as considered in the paper (financial and demographic indexing, $(\alpha=0.40)$;

2) the ten-years annuity with only the financial indexing $(\alpha=0.40)$;

3 ) the ten-years life annuity with constant unitary installments;

4) the ten-years utility-equivalent annuity. As an example considered for an individual normally patient and with medium risk aversion, with constant installments equal to 1.203625 (case of Vasicek interest rates).

\section{Final Remarks and Future Developments}

We sum up the results outlined throughout the paper. Referring to the values of AROE and ARG in figures and tables, and pointing up their informative potential, we can argue that the participating annuity we have depicted is characterized by a profitability for the insurer that, even when strictly decreasing as in the AROE case, moves within a narrow interval and tends to steady right from the second half of the contract duration. The trend of the AROE index represented in its worst cases by means of the $\mathrm{C}$-quantiles points out these considerations. The ARG increasing trend shows the improving performance of the business in the profitability of its assets. The range of ARG and AROE values is narrower when $\alpha$ is higher. The negative impact of higher values of the participating quota is clear and easily conceivable.

The aforesaid analysis mainly focuses on the insurer's point of view. Nevertheless, it is important to point out conceivable motives from the insureds' perspective. In our numerical example we can observe that the projected survival probabilities fit well the observed ones, so the survival index is always greater than 1 . Nevertheless, the paper does not neglect the point of view of the insured, an aspect more and more relevant in the product efficiency analysis. The topic is deepened in the Utility Equivalent Annuity framework, providing tables quantifying the perception of the new product in terms of the traditional one. In our example, on the base of different degree of risk aversion and of subjective discount factor, the analysis points out that in any case the insured considers equivalent to the new variable product, a traditional annuity with benefits larger than 1. A table reports the single premiums of comparable annuities and a graph designs the trend of the expected life-time utility.

We think that this research line could be certainly interesting in a context paying more and more attention to the insurance product profitability combined with the unavoidable consumer care. In the paper we outline the scheme for a clear analysis of a new life insurance product, consisting in three basic steps: the product analytical description, the study of the its profitability from the point of view of the insurer and the exam of the product perception on the part of the insured, in order to have a measure of their potential interest in the product itself.

\section{References}

[1] EIOPA Publications (2012). 
https://eiopa.europa.eu/Publications/Reports/EIOPA_ANNUAL_REPORT_2012.pd f

[2] Dorofti, C. and Jakubik, P. (2015) Insurance Sector Profitability and the Macroeconomic Environment. EIOPA Reports.

https://www.google.it/?gws_rd=ssl\#q=Dorofti\%2C+C.\%2C+Jakubik\%2C+P.+(2015

$\underline{\text { +Insurance }+ \text { Sector+Profitability+and+the+Macroeconomic+Envi-ronment.+EIO }}$

$\underline{\mathrm{PA}+\text { Reports }}+$

[3] Easton, A.E. and Harris, J.F. (2007) Actuarial Aspects of Individual and Annuity Contracts. 2nd Edition, Actex Publication Inc., New Hartford.

[4] Andreu, L. and Swinkels, L. (2012) Performance Evaluation of Balanced Pension Plans. Quantitative Finance, 12, 819-830.

https://doi.org/10.1080/14697681003762289

[5] Gatzert, N. and Wesker, H. (2012) The Impact of Natural Hedging on a Life Insurer's Risk Situation. Journal of Risk Finance, 13, 396-423.

https://doi.org/10.1108/15265941211273731

[6] EIOPA Financial Stability Report (December 2015). https://eiopa.europa.eu

[7] Penga, J., Leungb, K.S. and Kwokc, Y.K. (2012) Pricing Guaranteed Minimum Withdrawal Benefits under Stochastic Interest Rates. Quantitative Finance, 12, 933-941.

[8] D’Amato, V., Di Lorenzo, E., Orlando, A., Russolillo, M. and Sibillo, M. (2013) Profit Participation Annuities: A Business Profitability Analysis within a Demographic Risk Sensitive Approach. Investment Management and Financial Innovations, 1, 155-165.

[9] Coppola, M., Di Lorenzo, E., Orlando, A. and Sibillo, M. (2007) Measuring Demographic Uncertainty via Actuarial Indexes. In: Skiadas, C.H., Ed., Recent Advances in Stochastic Modelling and Data Analysis, World Scientific Publishing Co. Pte Ltd., Singapore, 122-129. https://doi.org/10.1142/9789812709691_0015

[10] Coppola, M., Di Lorenzo, E., Orlando, A. and Sibillo, M. (2011) Solvency Analysis and Demographic Risk Measures. Journal of Risk Finance, 12, 252-269. https://doi.org/10.1108/15265941111158451

[11] O’Brien, C.D. (2004) Surplus in Life and Pension Insurance. In: Teugels, J.L. and Sundt, B., Eds., Encyclopedia of Actuarial Science, Vol. 3, Wiley, Hoboken, 16401645. https://doi.org/10.1002/9780470012505

[12] Mahanyni, A. and Steuten, D. (2013) Deferred Life Annuities: On the Combined Effects of Stochastic Mortality and Interest Rates. Review of Managerial Science, 7, 1-28. https://doi.org/10.1007/s11846-011-0066-5

[13] Rocha, R., Vittas, D. and Rudolph, H.P. (2011) Annuities and Other Retirement Products: Designing the Payout Phase. The World Bank, Washington DC. http://www.iopsweb.org/researchandworkingpapers/48266689.pdf https://doi.org/10.1596/978-0-8213-8573-9

[14] Beal, R.W. (2002) Bridging the Gap between ROE and IRR. The North American Actuarial Journal, 4, 1-11.

[15] Maurer, R., Rogalla, R. and Siegelin, I. (2013) Participating Payout Life Annuities. Lessons from Germany. ASTIN Bulletin, 43, 159-187. https://doi.org/10.1017/asb.2013.10

[16] Hari, N., de Waegenaere, A., Melenbergb, B. and Nijman, T.E. (2008) Longevity Risk in Portfolios of Pension Annuities. Insurance: Mathematics Economics, 42, 505-519. https://doi.org/10.1016/j.insmatheco.2007.01.012

[17] Tan, K.S., Blake, D. and MacMinn, R. (2014) Longevity Risk and Capital Markets: 
The 2013-2014 Update.

https://www.google.it/url?sa=t\&rct=j\&q=\&esrc=s\&source=web\&cd=1\&cad=rja\&ua $\mathrm{ct}=8 \& v e d=0$ ahUKE-wixy9uRnrjRAhWWM1AKHUUUASIQFggaMAA\&url=http $\%$ 3A\%2F\%2Fwww.pensions-institute.org\%2Fworkingpapers\%2Fwp1502.pdf\&usg=A FQjCNHSkoeWpogjyApCSJHCrYs9I4C79w\&bvm=bv.143423383,d.ZWM

[18] Richter, A. and Weber, F. (2011) Mortality-Indexed Annuities. Managing Longevity Risk via Product Design. The North American Actuarial Journal, 15, 212-236. https://doi.org/10.1080/10920277.2011.10597618

[19] Piggott, J., Valdez, E. and Detzel, B. (2005) The Simple Analytics of a Pooled Annuity Fund. Journal of Risk and Insurance, 72, 497-520. https://doi.org/10.1111/j.1539-6975.2005.00134.x

[20] Denuit, M., Haberman, S. and Renshaw, A. (2011) Longevity-Indexed Life Annuities. The North American Actuarial Journal, 15, 97-111. https://doi.org/10.1080/10920277.2011.10597611

[21] Lee, R.D. and Carter, L.R. (1992) Modeling and Forecasting US Mortality. Journal of the American Statistical Association, 87, 659-671.

[22] Vasicek, O. (1997) An Equilibrium Characterisation of the Term Structure. Journal of Financial Economics, 5, 177-188. https://doi.org/10.1016/0304-405X(77)90016-2

[23] EIOPA Consumer Protection (2015). https://eiopa.europa.eu/consumer-protection

[24] EIOPACP16/001 (2016) Consultation Paper on EIOPAs Advice on the Development of an EU Single Market for Personal Pension Products (PPP). http://www.slideshare.net/EthosMedia/cp-16001-eiopa-personal-pensions

[25] Knoller, C. (2016) Multiple Reference Points and the Demand for Principal-Protected Life Annuities: An Experimental Analysis. The Journal of Risk and Insurance, 83, 163-179. https://doi.org/10.1111/jori.12101

[26] D’Amato V., Di Lorenzo, E., Orlando, A. and Sibillo, M. (2016) Life Annuities Portfolios: Risk-Adjusted Valuations and Suggestions on the Product Attractiveness. Proceedings of the 4th Stochastic Modeling, Techniques and Data Analysis International Conference, Valletta, 1-4 June 2016, 123-131.

\section{Submit or recommend next manuscript to SCIRP and we will provide best service for you:}

Accepting pre-submission inquiries through Email, Facebook, LinkedIn, Twitter, etc. A wide selection of journals (inclusive of 9 subjects, more than 200 journals) Providing 24-hour high-quality service User-friendly online submission system Fair and swift peer-review system Efficient typesetting and proofreading procedure Display of the result of downloads and visits, as well as the number of cited articles Maximum dissemination of your research work

Submit your manuscript at: http://papersubmission.scirp.org/ Or contact jmf@scirp.org 